\title{
On the Implementation of Transfers to Subnational Governments
}

\author{
Ehtisham Ahmad and Bob Searle
}




\title{
IMF Working Paper
}

Fiscal Affairs Department

\section{On the Implementation of Transfers to Subnational Governments}

\author{
Prepared by Ehtisham Ahmad and Bob Searle ${ }^{1}$
}

June 2005

\begin{abstract}

\section{This Working Paper should not be reported as representing the views of the IMF.}

The views expressed in this Working Paper are those of the author(s) and do not necessarily represent those of the IMF or IMF policy. Working Papers describe research in progress by the author(s) and are published to elicit comments and to further debate.

This paper examines a typology of grants that are used across the world, and places these in the context of the overall constitutional and legal framework for a country. It looks at the options for grants, given the need to maintain overall macroeconomic stability, efficiency in the use of scarce resources as well as reduced horizontal disparities. The role of central objectives in a decentralized framework is also assessed. The paper argues for a comprehensive framework for grants, as well as a proper institutional framework to manage grants systems.
\end{abstract}

JEL Classification Numbers: H77

Keywords: Intergovernmental Fiscal Relations; Grants

Author(s) E-Mail Address: eahmad@imf.org; bob.searle@bigpond.com

\footnotetext{
${ }^{1}$ Ahmad is with the International Monetary Fund and Searle is a former Secretary of the Commonwealth Grants Commission, Australia. We are grateful to participants at a seminar in Torino and particularly to Giorgio Brosio for helpful comments
} 


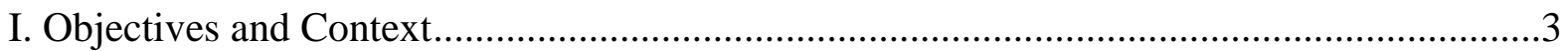

Equalization transfers or transfers to individuals? ......................................4

II. Legal and Institutional Framework for Transfers .....................................................4

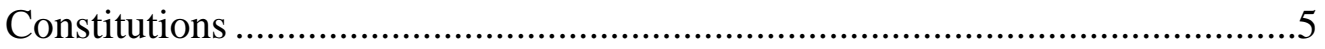

Specific legislation..............................................................................

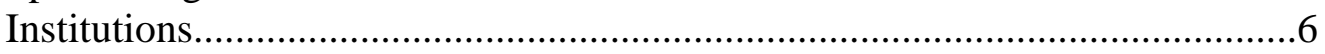

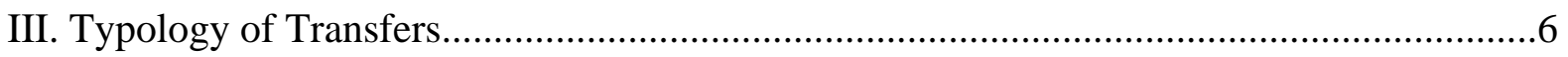

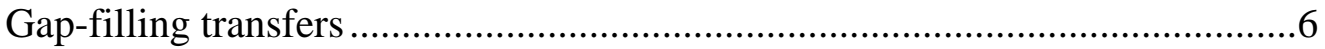

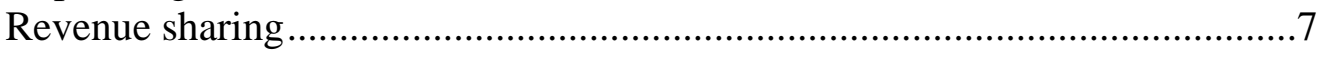

Special purpose grants ..................................................................

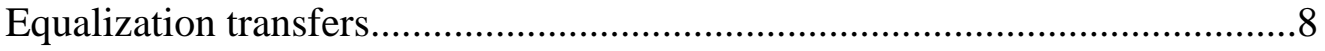

IV. Mechanisms for the Determination of Equalization Grants ........................................11

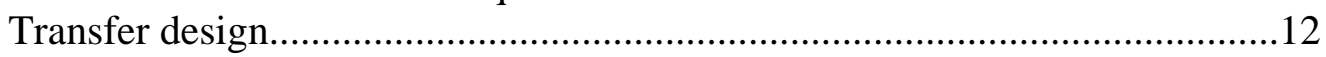

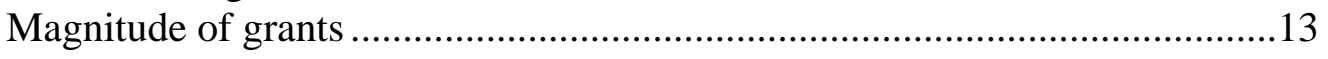

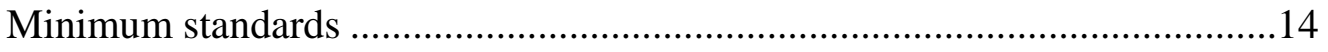

A general model for equalization transfers ..............................................15

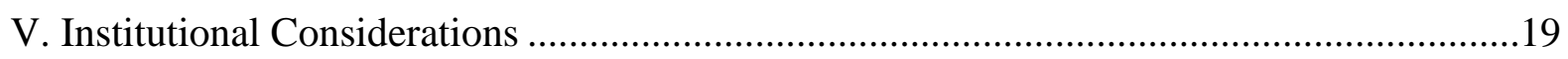

Institutional arrangements, organization and procedures ...........................19

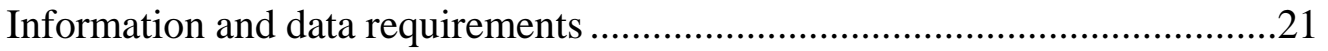

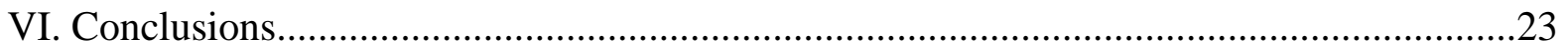

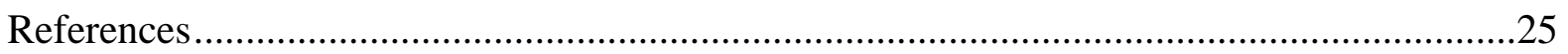




\section{OBJECTIVES AND CONTEXT}

A variety of grants instruments are observed across the globe. The magnitude and types of grants depend considerably on the context — often on the extent to which subnational administrations have access to adequate own-source revenues in relation to their constitutional or assigned responsibilities. Grants may also serve to address the policy objectives of higher levels of government. And, as both revenue assignments and expenditure responsibilities are frequently reviewed or reformed, even in the developed countries, there needs to be a constant evaluation of the need for transfers and the mechanisms used to implement grants systems. While there are attempts to institutionalize the arrangements for determination of grants, it is evident that political economy considerations play a significant role in the design of grants systems. However, poorly designed grants systems can have a negative impact on incentives for efficient management of public finances as well as on overall macroeconomic outcomes.

Grants to subnational governments are used to serve multiple goals. Often these goals are partially unrelated and they can be conflicting. They include:

- $\quad$ equity considerations and the reduction (or elimination) of vertical and horizontal imbalances;

- $\quad$ the correction of spillovers;

- $\quad$ the implementation of centrally determined standards for public services; and

- $\quad$ the enhancement of tax effort and expenditure efficiency.

To reconcile these goals, combinations of revenue sharing, special-purpose, and general-purpose grants tend to be used. Revenue sharing is often used to address vertical imbalances. General purpose or unconditional grants are useful in the reduction of horizontal disparities. And special-purpose, or conditional grants are used for fostering national priorities and to serve specific, efficiency enhancing goals. ${ }^{2}$

This paper focuses on transfer instruments and their implementation, and complements that by Boadway, which examines the efficiency and equity considerations underlying transfer design. We examine first a typology of grants, followed by greater details on an equalization framework. A final section examines practical issues of implementation of a general grants system, as well as the constraints on relying on different types of grants.

\footnotetext{
${ }^{2}$ See, for example, Shah (1995), and Boadway (forthcoming).
} 


\section{Equalization transfers or transfers to individuals?}

Some argue that the objective of fiscal equalization through general-purpose grants should be to equalize personal incomes within and across regions. However, the equalization of personal incomes may be neither feasible nor desirable. Equalization of incomes did not work in the centrally planned economies, for instance in the former Soviet Union, ${ }^{3}$ any more than it does in advanced market economies, most of which display relatively stable degrees of interpersonal inequality. Should governments target a certain level for the Gini coefficient and resulting distribution of income? It is difficult to make a case for this. At best, prevention of need and destitution might be at the centerpiece of government objectives, and for which there might be more or less effective direct programs-pensions for the aged, assistance for families with children (family allowances in some countries), help for the unemployed, and so on-while market forces determine the final outcomes. Some of these policy objectives could be met through special-purpose grants, if actual provision or implementation is by subnational governments. However, an excessive reliance on financing subnational spending through special-purpose transfers might conflict with or circumscribe subnational decision making.

A more defensible objective for fiscal equalization would be to facilitate the provision and access to public services, by subnational governments, at similar levels of tax effort (these are effectively the objectives of equalization systems in countries as diverse as Australia and Denmark. ${ }^{4}$ This focus on potential access to services preserves a degree of autonomy for subnational jurisdictions.

\section{LEGAL AND INSTITUTIONAL FRAMEWORK FOR TRANSFERS}

The design of transfers or the context for the determination of transfers is often enshrined in constitutions or higher laws (where applicable, requiring more than a simple majority for amendments). Details that might be subject to frequent revision would typically be determined in regulations or pronouncements of special bodies that might be set up by a higher authority. The magnitude of the transfers, as well as the combination of instruments, might be specified in the higher legislation, or in annual budget laws reflecting changing macroeconomic considerations. Further, special-purpose grants are often associated with special laws defining specific programs, for example, in health care or education. Donors or international bodies might also be responsible for the introduction or diversification of special-purpose grants for basic services (e.g., to meet Millennium Development Goals), or investments in the social sectors, or infrastructure.

\footnotetext{
3 Ahmad, 1993.

${ }^{4}$ See Ahmad, 1997, and papers by Rye and Searle (on Australia) and Løtz, 1997 and 2005 (on Denmark and the other Scandinavian countries).
} 


\section{Constitutions}

Older constitutions mainly focused on separation, or concurrent access to distinct tax bases, or sharing of a pool or individual taxes, or specification of responsibilities.

Many modern constitutions refer to the principles and mechanisms of transfers. There are advantages for the main principles of a transfer system to be enshrined in constitutions or in higher-level legislation, in order to provide clarity in functions and roles, as well as financing mechanisms. However, several constitutions recognize that change is inevitable, and provide for periodic assessments (e.g., the Indian and South African Constitutions require quinquennial assessments by dedicated Finance Commissions). ${ }^{5}$ Reassurance that adequate resources would be forthcoming for subnational levels of government, including a share of natural resources as well as transfers, as in Nigeria, have been seen as an ingredient in keeping the federation together. ${ }^{6}$

In other cases, particularly in some Latin American countries, detailed specification of formulae or floors on transfers in constitutions can generate undesirable rigidity that might considerably complicate macroeconomic adjustment. There is however a fine balance between reassurance to subnational administrations and flexibility for changing circumstances, refinements of data and methodology, and macroeconomic vicissitudes.

\section{Specific legislation}

Countries that have had a long or strong tradition of centralized operations (e.g., Indonesia, France, and most recently, Peru) have sought to support a decentralization process through legislation that both specifies responsibilities and administrative arrangements, as well as the fiscal aspects, including the sharing of resources, as well as the design and floor on transfers.

As subnational capacities are built up, it might become feasible to devolve functions gradually to lower levels without risking a negative impact on service delivery. Under these circumstances, the flexibility in the design of transfers might be useful-as countries are typically reluctant to amend constitutions, except in extreme crises-and the appropriate legal instrument may be a higher-level (where applicable) or specific legislation that might be easier to amend than a constitution, while at the same time providing assurance of continuity and a framework for the management of subnational public finances. Such "framework" legislation would be supplemented by detailed appropriations in annual budget laws, or specific laws governing special-purpose programs, often with a multiyear impact.

\footnotetext{
${ }^{5}$ In the Indian context, new Finance Commissions are constituted every five years, whereas the South African Fiscal and Financial Commission is a standing body.

6 The sharing of volatile revenues (e.g., from petroleum and gas) can introduce considerable uncertainty in the budget process of lower levels of government that they are usually ill equipped to handle, especially in less developed countries (see Ahmad and Mottu, 2003).
} 
As legal frameworks tend to vary, there is a tension between overspecification (e.g., of details or floors in constitutions) providing assurance to the subnational levels of administration, and flexibility that might be needed for macroeconomic management and tailoring the intergovernmental arrangements to changing circumstances. In either case, the establishment of arms' length coordination and dispute resolution bodies are important to establish a framework and parameters for discussion.

In many overdetermined legal frameworks, there have been attempts to instill macroeconomic discipline by placing constraints on subnational operations through fiscal responsibility legislations applying to all levels of government (see Ahmad, Albino-War and Singh, ?). Depending on the political and legal context, if higher-level legislation (e.g., the constitution) permits spending by lower level administrations, regulations would not effectively constrain such spending. Introducing regulations, instead of tackling the lacunae in higher-level legislation, reflects the political weaknesses of the system, and the overall framework might not be defensible against a serious challenge by a lower level administration. Under these circumstances, it might be safe to assume that subnational administrations will spend all their assigned revenue shares and other transfers, and the burden of adjustment would perforce fall on the central government.

\section{Institutions}

Under circumstances where the vertical imbalance in favor of the center is small, there is generally little that the central or federal government can do to redress horizontal imbalances. Institutions that facilitate transfers or redistribution across regions are thus likely to be important under such circumstances, and national identity, solidarity, and traditions come into play, as in Germany. It is unusual to find such arrangements in countries with sharp ethnic, linguistic, or other divisions.

The role of a central government in redistribution increases if there is a large vertical imbalance in its favor. Under these circumstances, check and balances are generally needed to assure the subnational administrations that there will be fairness in the redistribution process, as well as predictability and certainty in the transfer design in order to finance the basic expenditures that are typically assigned to subnational administrations. We examine certain options for such institutions in the context of equalization transfers described in greater detail below.

\section{TyPOLOGY OF TRANSFERS}

There are a variety of transfers possible and each tends to have a different implication for incentives and distribution.

\section{Gap-filling transfers}

Transfers to finance deficits at the subnational level between own-revenues and spending are commonly known as "gap-filling." If subnational governments have carte blanche in this respect, there is no effective budget constraint, hence no incentive to manage spending or 
raise revenues efficiently at the subnational level. Such transfers were common for instance in South Asia, and Govinda Rao (2002) has pointed to the deleterious effects of such "fiscal dentistry.” Such arrangements are now increasingly rare.

\section{Revenue sharing}

Revenue sharing (e.g., for the value-added tax (VAT)) is used often used to partially offset vertical imbalances. ${ }^{7}$ In Germany, the VAT is shared on a per capita basis. Revenue sharing bears characteristics of transfers, as the subnational governments have little control over bases or rates.

In general, however, revenue sharing tends to be on the basis of the origin of the revenues, as in China, which may exacerbate horizontal inequalities. Similarly, the devolution of revenue bases to subnational jurisdictions does little for subnational governments with poorer bases or higher costs of service provision-thus horizontal equalization remains a problem to be addressed.

An extreme example is the case of Australia, which recently introduced a national VAT — the general sales tax - to replace a range of inefficient state-level taxes (including sales taxes) and the Commonwealth wholesale sales tax. The political arrangement to facilitate this change was to place the entire amount of VAT revenue as the source of funds to be distributed back to the states through the equalization transfer system (see below).

\section{Special purpose grants}

Reliance on special-purpose programs (SPPs) to further central government policy objectives and to correct for spillovers is universally recognized. The SPPs could be open-ended, reflecting continuing legislation, or close-ended, such as for specific projects.

Some conditional grants may have matching requirements from the recipient administrations (see Boadway and Hobson 1993 for a detailed exposition). While matching requirements might induce greater effort on the part of recipients, this could cause distortions leading to less spending elsewhere, with possibly deleterious effects on the overall welfare of the recipient populations. In other cases, such as in Denmark, matching grants have been criticized as leading to greater spending as well as additional taxation (Lotz, 2005). In developing countries, limited revenue bases could restrict the take up of the grant in poorer regions, and could widen horizontal disparities.

In practice, the excessive reliance on earmarked transfers, particularly in Latin American countries, has led to mixed outcomes and effectively reduced accountability on the part of subnational administrations. In extremis, such transfers could be construed as interference by the center often in areas of subnational competence. In developed countries, very detailed

\footnotetext{
${ }^{7}$ This is also an administratively neutral way of sharing VAT revenues—as separate subnational VATs pose administrative difficulties.
} 
earmarking has been generally replaced by looser sectoral conditionality leading to an emphasis on block grants that require that the funds be used say for education, but with greater flexibility on the precise spending items to be determined by the recipient government.

Central governments in developing countries often lack the ability to monitor the use of conditional grants. If there is poor information on the implementation of the earmarked grants, then this could degenerate into additional finance for a subnational government, but without the local accountability that might be expected of local government's spending from own-source revenues or untied transfers. There may, however, be scope for inducing enhanced management and reporting on conditional grants, if these are designed as repeated games or contracts. This is an area for fruitful research.

\section{Equalization transfers}

Most large countries (many smaller ones as well, for example, Belgium and Denmark) practice forms of fiscal equalization. Indeed, much depends on the basic allocations of taxation functions and spending powers of specific jurisdictions, often specified in constitutional, legal, or institutional arrangements. Given externalities in centralized tax administration, many countries assign the main tax heads to the center, including corporate and income taxes, customs, and the VAT. With an increasing pressure to decentralize expenditure responsibilities, the result is a greater vertical imbalance that generates a need for grants.

\section{Equalization over revenues}

Countries such as Canada have traditionally instituted equalization transfer systems based on revenue capacities. It had been argued that there were no significant differences between the service delivery levels across most Canadian provinces, hence it was sufficient to equalize across revenue capacity only (Representative Tax System, RTS). ${ }^{8}$ However, more recently, it has been recognized that service delivery costs are higher in the Northwestern Territories than in the rest of Canada, and a special grant has been constituted for this purpose.

Moreover, special purpose grants, especially for health care and education-essentially meeting central government objectives — are based on needs criteria, and their magnitude outstrips that of equalization. ${ }^{9}$

Changing tax assignments and additional own-revenue powers for the Canadian provinces, which now have access to all the major tax bases available to the center, call into question the scope of any vertical imbalance, as the provinces should in principle be able to compensate for any loss of central revenues by raising their own taxes.

\footnotetext{
${ }^{8}$ See Clark (1997). The exclusion of natural resource revenues accruing to the provinces under the 5-province formulation of the RTS also weakens the conceptual basis for the system.

${ }^{9}$ See Aubut and Sample (forthcoming).
} 
Further, the recent move to fix the amount of the equalization payments for a period of ten years effectively replaces the RTS. This has led to a decision to reconsider the formulation of the RTS and the overall equalization framework, including whether it should be based on a revenue-only equalization basis. The treatment of the center's significant “individual-based” programs in an equalization framework might also be evaluated. In general, equalization over revenue capacities only might not be an appropriate option for large or disparate countries with significant differences in the cost of provision of public services.

\section{Equalization over needs}

Some countries have chosen to equalize over expenditure needs alone for subnational governments. This could be ascribed more to the inadequate own-source revenues at the subnational level, rather than any other theoretical consideration. Expenditure needs in isolation from own-source revenues tend to weaken budget constraints. This is the case in South Africa ${ }^{10}$ (although it could be argued that the "economic output" variable in its calculation might be seen as a proxy for revenue capacity differences). ${ }^{11}$

The lack of provincial revenue raising ability in South Africa constrains the design of the horizontal equalization program and also means that the national government cannot encourage efficient use of resources (e.g., through the use of matching grants). The Financial and Fiscal Commission (FFC) has therefore suggested that a "cost-based" approach should be developed that would force provinces to recognize the true opportunity cost of reallocating resources. ${ }^{12}$ The cost-based approach, by providing a rational basis for a firm and binding provincial budget, should force these governments to take account of the reduction in other services implied by an increase in any given service. Thus, it argues that this approach is the best available instrument for encouraging provinces to make efficient budgetary decisions. Each provincial government would then have a strong incentive to find innovative, cost-saving ways to meet the social service goals specified by the national government. Because the basis for allocating nationally raised resources to each province is a measure of costs that reflects the underlying social conditions in each province, for example, the number of students and the rate of poverty, equitable share allocations to provinces that develop more efficient methods for delivering government services should not be reduced. However, existing spending patterns across the provinces reflect a combination of factors, including historical patterns of public service delivery, cost differences, and inefficiencies in the delivery of services. For this reason, to the extent that the allocation of the equalization transfers in South Africa reflects current expenditure levels, the allocations may serve to reinforce both provincial government inefficiencies and historical patterns of public service provision, and may not lead to either fiscal equalization or equality in service provision. In Italy, there was little incentive for enhanced efficiency in the period that the government

\footnotetext{
${ }^{10}$ Provincial governments only raise about 5 percent of their revenues.

${ }^{11}$ For local governments, which have access to own-source revenues, there is some fiscal capacity equalization.

${ }^{12}$ See www.ffc.co.za for more details.
} 
relied solely on expenditure needs - the introduction of revenue capacity considerations was important (see Brosio, 1995).

In general, while the expenditure needs only approach is to be preferred to gap-filling transfers, the use of historical factors might not facilitate efficiencies, and the absence of reliance on own-source revenues at the margin reduces significantly the incentives for increased efficiency.

\section{Equalization based on revenue capacities and expenditure needs}

In an increasing number of countries, equalization systems take into account both revenue capacities and expenditure needs. This allows for moves towards equalizing the capacity of subnational administrations to provide access to public services at similar levels of revenue effort. This formulation addresses the difficulties associated with the abstraction from differential costs of services associated with a revenue-only approach, or the incentive problems or possible inefficiencies that might persist in an expenditure needs-only approach. This model has been adopted in many other countries, including those as diverse as Australia and Denmark, and more recently in China and Ethiopia. Yet the Australian system is also evolving, reflecting a political economy give and take between the center and the states over the control over resources.

An issue that might militate against applications of the Australian model is the complexity of the estimation of relative costs. ${ }^{13}$ The greater complexity currently reduces the transparency and attractiveness of the logic of the approach.

The political economy of the introduction of an equalization transfer system can also be seen in the case of China. In 1994, an equalization transfer system, based on the Australian model, but with relatively simple factors, was introduced to accompany a new revenue-sharing arrangement. While many of the objectives of the reform were met, including overall revenues and increasing the share of the central government, the equalization potential of the transfer system has still to be realized-given the needs and political power of the relatively well-to-do coastal provinces the central government did not realize the fiscal space to redistribute to a significant extent (see Ahmad, Fortuna, and Singh, 2004).

Impending tax reforms ${ }^{14}$ and clarification in expenditure responsibilities will facilitate the reconsideration of the transfer system and its objectives, as well as design issues. The

\footnotetext{
${ }^{13}$ In its Report on State Revenue Sharing Relativities, 2004 Review, Australia's Commonwealth Grants Commission has recommended that there be work undertaken to simplify the determination of its equalization-based grants to state governments.

${ }^{14}$ For instance, a rationalization and reassignment of the income tax or the likely reform of the investment VAT to a more standard consumption-based VAT, are policy measures that will have an impact on the share of revenues accruing to subnational governments in China, and cannot be achieved without a corresponding adjustment of the transfer system or rationalization of spending assignments (Ahmad, Lockwood, and Singh, 2005).
} 
Chinese case illustrates that even with a well-coordinated process of policy reforms, there are evident interactions between policy instruments, and that it is neither desirable, nor indeed possible, to ignore political economy constraints and the interests of regions that are instrumental in generating growth and employment.

One issue that remains is whether the grant programs initiated by the central government to achieve its own policy aims should be taken into consideration in estimating the equalization transfers. In the extreme case, central governments might be better advised to use such special-purpose grants rather than equalization transfers to meet horizontal equalization objectives. In the Chinese context, the difficulties with the "equalization" system have led the authorities to turn to regional development programs, as for the West China Development initiative. In general, the reliance on special-purpose transfers is limited by weak or absent capabilities to monitor the use of the special funds according to agreed objectives.

\section{MECHANISMS FOR THE DETERMinAtion OF EQUALIZATION GRANTS}

A common goal in the use of unconditional grants is to allow beneficiary governments to provide access to equal — or at least comparable-levels of public services, taking account of the relative capacity of those governments to fund the provision of services.

The capacity to finance similar levels of services is not, however, only a function of the level of revenues. It also depends on the cost of producing the services, as well as on differences in the possible demand for those services (need). In other words, two local governments with the same per capita revenue capacity may not have the same capacity to satisfy the service needs of their population if their populations have different expenditure needs, resulting, for example, from differences in the proportions of young or elderly people and/or if they are confronted with different costs of providing these services, such as those arising from population density and climatic conditions.

The attenuation of the most blatant disparities between jurisdictions in levels of service provision requires filling any inequalities in infrastructure and capital stock. While in principle a single transfer scheme without distinction for recurrent and capital expenditure can be envisaged, the separation of recurrent from capital transfers may be more appropriate to the present conditions of many low- and middle-income countries. Scarcity of financial resources and popular pressure to use them for immediate current spending may leave little for capital formation. Under these circumstances, a separate capital transfer scheme is often beneficial.

The aim of instituting capital transfers, especially in poor countries, would be to start to fill backlogs in capital stock. This mechanism should also reduce the need for the central government to carry out projects in areas of subnational competence. Capital transfers may be allocated according to the difference between the actual stock or condition of infrastructure and an agreed minimum standard.

Other basic requirements of a well-designed grant system are that it be based on a transparent formula and that the indicators used in the assessment should not reflect discretionary policy 
choices made by the recipient governments. For example, the total amount of salaries paid to local employees should not be considered as an indicator of need because beneficiary governments would then be induced to increase their wage costs in order to get a larger share of the grant.

Many federal countries, such as Australia and Switzerland, and a growing number of advanced unitary countries, such as the Scandinavian countries and the United Kingdom, use a grants framework based on expenditure needs and revenue capacity to ensure that local governments have sufficient revenue to provide reasonably comparable levels of public services at comparable levels of taxation. The adoption of the expenditure-needs and revenue-capacity approach presents considerable advantages for most developing countries. It allocates the total amount of transfers among distinct subnational governments in a way that promotes efficiency and accountability; provides a known basis for the vertical allocation of national revenue among the different levels of government; and stimulates accountability by providing yardsticks against which subnational performance can be evaluated by the various stakeholders, namely citizens, auditing bodies, and upper levels of government that provide finance.

There are, however, a number of political and technical issues that have to be addressed for its implementation, and its financial sustainability has to be assessed against the amount of resources available.

\section{Transfer design}

One of the key questions for the operation of a system of equalization grants is whether it is to be based on both expenditure needs and revenue capacities. Decisions will also be needed in the design of the equalization system as to whether or not account should be taken of the interactions with any special-purpose grants.

The importance of an effective general transfer system based on an objective of fiscal capacity equalization could be described as "the glue that holds the nation together." It is based on the simple proposition that all people of a nation are entitled to a reasonably similar standard of government services so that people in remote regions can have access to, say, educational opportunities and health care at a standard not too dissimilar to those in the larger cities.

There are a number of important issues to be decided in designing such a transfer system. One key question will be whether to assess absolute needs or relative needs. In many countries, the determination of general-purpose grants is a relative process. In Australia, for example, the capacities of the states are equalized to the average level (per capita) of service provision, assuming the application of average effort to raise revenue. It would, however, be possible if sufficient resources were available, to equalize to an absolute or minimum standard (such as the provision of nine years of education) which all regions should aspire to achieve, but it is usually more practical to use tied grants to raise standards where they fall short of national minima. 
There is also a question of accountability. Most grants systems, particularly in larger, more diverse countries, operate through general-purpose (untied) grants. This enables different units of government at the same level to develop different methods of service provision to best suit their circumstances and the aspirations of their people. Questions about the applicability of a general-purpose grant system arise in countries where the accountability mechanisms, including information on what has been spent is weak, and outputs or outcomes difficult to monitor. However, similar objections could be posed in relation to a grant system based on special-purpose grants, with limited information on what has actually transpired. Typically, special-purpose grants are more demanding of information and reporting mechanisms, and if these are weak, a simple equalization framework might be preferable.

In most countries, some degree of flexibility is considered necessary. For example, where the units of government to receive grants are small in terms of financial capacity, it may well be desirable to give them scope for cooperative efforts in service provision. A very small district is likely to find it more efficient to contract out some services to neighboring regions or to another level of government (or the nongovernment or private sector) rather than trying to provide everything itself.

The grants systems of many countries rely on the identification and estimation of disabilities (influences beyond a government's control that affect what it needs to spend on providing services or can raise from a particular kind of taxation). However, too many factors or indicators are likely to reduce the transparency of the system and could also erode general acceptability of a "black box" approach, including in developed countries.

Most developing countries also lack the statistical base for more complex methods or models. However, the use of a few simple indicators (such as the proportions of relevant populations, like school age children or the elderly) is likely to be all that is feasible, and can provide adequate redistributive transfers. Such systems can be elaborated over time with the development of databases, administrative capabilities, and technical expertise.

\section{Magnitude of grants}

An overarching issue is how to decide on the quantum of funds to be devoted to general-purpose grants. In theory, "full" equalization can be based on any level of services, but resource constraints ensure that few countries, and particularly developing countries, can achieve "full" equalization at the standards of service to which they aspire. The overall budget constraints and other macroeconomic considerations limit the ability of the central government to provide sufficient resources to close horizontal gaps.

A number of countries target less than full equalization, often with an absolute floor on the equalization transfer depending on what essential services are to be covered in the general grant formulation. This variation was introduced in the Indonesian legislation of 1999 that provides the lower level of governments, which have limited sources of own-source revenues, with an assurance that at least 25 percent of total central government revenue will be distributed to them. The important issue here is whether the quantum of funds distributed through the unconditional grants pool is sufficient to fulfill the objectives of the 
unconditional grants. The pool size must therefore be related to the fiscal capacity inequalities in the recipient governments.

\section{Minimum standards}

Developing countries often face a choice concerning minimum levels of service deliverythis is so in Nigeria, South Africa, and many other developing countries. The method of estimating expenditure needs in terms of “costed minimum standards" consists of estimating, for each unit of government, the resources needed to provide an agreed minimum standard of service level to the population (and is seen to be a special case of the general formulation).

In a federal or otherwise decentralized nation, the determination of the standards by the central government in isolation would be inappropriate, since the final outcome depends on effective participation of the other levels of government. Standards would need to be agreed among the concerned levels of government. This calls for consultation and agreements. Local governments might participate in consultative bodies and the participation of representatives of every level of government in the decisions concerning them is widely practiced across the world. For example, many European Union member countries have consultative and/or participative bodies for the implementation of the "Stability Pact." Federal countries, such as Australia, ${ }^{15}$ India, and South Africa have similar intergovernmental bodies. Another issue relates to the choice of the appropriate instruments. Standards (and priorities) may be set up by using several instruments. The first mechanism for defining standards for service provisions is in terms of the inputs of the services. This is the most common method, and teacher/pupil ratios are a typical example. The main advantage of input-based standards is that they are easy to determine.

The second way of defining standards is in terms of outputs or outcomes. For example, the water distribution service has to provide clean water to all connected households with a view to improving health standards. The output, clean water, is easier to quantify than the outcomes, although the latter more naturally reflects the objective of public policy. Output or outcome-based budgeting typically leaves the choice of inputs and their combination to the producing or providing governments. Output levels are, however, often difficult to define in a noncontroversial way and are not easy to enforce. While many developing countries aspire to output-based decision making and budgeting, they lack the basic expenditure management tools and information flows, as well as audit and control mechanisms, which are needed to make such approaches viable. Outcome-based systems are even more difficult to implement. Because of these considerations, input-based standards are applied in most cases. Issues involved in estimating costs are described in the following section.

\footnotetext{
${ }^{15}$ Australia has a large number of Ministerial Councils that include the central government minister and all state ministers (and sometimes also the relevant minister from New Zealand). Each of these Ministerial Councils is supported by a committee of relevant officials.
} 


\section{A general model for equalization transfers}

A general model to estimate equalization grants would involve an evaluation of both relative revenue capacities and relative expenditure needs. Special cases of this model would include equalization:

- $\quad$ in respect of revenues only, without reference to expenditure needs; and

- $\quad$ based on expenditure needs alone.

The general model may be written as:

$$
G_{i}=E_{i}^{s}-R_{i}^{s},
$$

where $E_{i}^{S}$ represents relative expenditure needs of region i; and $R_{i}^{S}$ own-revenue raising capacity relative to a "standard.” In the Australian case, the issue of minimum standards is avoided within the equalization grant formulation and the standard is determined by the average expenditure levels across all states - the examples that follow reflect this formulation. In South Africa, a minimum expenditure standard is used. While there is some subjectivity in determining these minimum standards, this formulation may be meaningful in a developing country where the standard to which recipients are to be equalized may need to be higher than the level of service currently pertaining. While the absence of a revenue-capacities element reflects the existing revenue assignments, this may not matter if own-source revenue is insignificant, as in South Africa. It does, however, remain a constraint in moving towards greater accountability.

It is useful to decompose expenditure needs

$$
E_{i}^{s}=P_{i} \frac{E_{s}}{P_{s}} \cdot v_{i}
$$

where $P_{i}$ is the population of region $\mathrm{i}, E_{s} / P_{s}$ is the average expenditure standard in the country, and $v_{i}$ represents a number of independent factors that might be relevant for region $\mathrm{i}$, such as

$$
v_{i}=\left(u_{i} \cdot s_{i} \cdot d_{i} \cdot e_{i}-1\right),
$$

where, for example,

$\mathrm{u}_{\mathrm{p}}=$ differential coverage of the population eligible for services relative to the total population;

$\mathrm{i}_{\mathrm{s}}=\quad$ differential costs arising out of "scale" factors (that is, where larger size leads to reduce cost);

$\mathrm{d}_{\mathrm{i}}=\quad$ differential costs arising out of concentration or dispersion of the eligible 


$$
\begin{array}{ll}
\mathrm{e}_{\mathrm{i}}=\quad & \text { population; } \text { and } \\
\text { differences in cost arising out of social, physical and economic factors (for } \\
\text { example, higher costs in extremely cold or hot areas) }
\end{array}
$$

Whether positive or negative needs are assessed depends on whether $u_{i}, s_{i}, d_{i}$, and $e_{i}$, which are all based around the average jurisdiction's experience, exceed or fall short of unity. Where it is judged that there are virtually no differences in public service delivery standards or costs, this is equivalent to assuming that all regions face approximately the same costs in providing standard services (or that any such differences will be addressed through alternative means). In this case, the product of the items ( $u_{i}$, etc.) is about unity in all regions, and the expenditure term (2) goes to zero.

It is important to note that expenditure needs for equalization purposes must be attributable to unavoidable differences in costs of providing standard services, given different factors such as population size or density, and not to differences in policies or in the relative efficiencies with which services are provided. Recipient governments must not be able to influence the size of their assessed need.

Parallel to the assessment of expenditure needs, but requiring somewhat less in terms of data, is the estimation of own revenue capacity in region $\mathrm{i}, R_{i s}$,

$$
R_{i}^{s}=P_{i} \frac{R_{s}}{P_{s}} \cdot q_{i}
$$

where $R_{s} / P_{s}$ reflects “standard” per capita revenue collections, and $q_{i}$ is the differential

revenue raising capacity of region i, $q_{i}=\left(\frac{Y_{i}}{P_{i}}-\frac{Y_{s}}{P_{s}}\right)$, where $Y_{i}$ is the actual revenue base in

region $\mathrm{i}$. It is straightforward to relate $\mathrm{q}_{\mathrm{i}}$ to the standard revenue base, $Y_{s}$, by expressing (4) as

$$
R_{i}^{s}=P_{i} \cdot \frac{R_{s}}{Y_{s}}\left(\frac{Y_{i}}{P_{i}}-\frac{Y_{s}}{P_{s}}\right)
$$

Thus, the grants would relate a differential revenue-raising capacity relative to standard per capita revenue collection $R_{s} / P_{s}$.

The general formulation in equation (1) makes it clear that the capacity equalization grant depends on the magnitude of "net of variations" from the standard per capita expenditures and revenues. Such variations will be positive where there is a shortfall in revenue raising capacity, or regions face a higher per capita cost in providing standard services.

\section{Treatment of special-purpose grants and tax sharing arrangements}

Many countries use special-purpose grants and tax sharing arrangements while also having an equalization grant mechanism. These forms of financing a vertical fiscal imbalance must be taken into account in the calculation of the horizontal imbalances because they are 
revenue sources designed to meet some of the assessed expenditure needs, and differential grants or tax shares can offset or augment the differential own-source revenues identified under the capacity equalization arrangements. For example, equation (1) can be expanded to:

$$
G_{i}=P_{i} \cdot \frac{E_{s}}{P_{s}} \cdot v_{i}-P_{i} \cdot \frac{R_{i}}{P_{s}} q_{i}-\frac{O_{s}}{P_{s}} \cdot \sigma_{i}
$$

where

$$
\frac{O_{s}}{P_{s}} \cdot \sigma_{i} \text { is the differential special-purpose grant. }
$$

A decision to allow the regions to retain a share of the VAT collected on a derivation basis, for example, would provide sustained advantages to more developed regions. If the equalization objective was to be upheld, the VAT would be assessed as part of the each regions" "own revenue" resources, and an above-average fiscal revenue raising capacity assessed in the more developed regions. Alternatively, the assessment for equalization purposes could be restricted to own-source revenues and the shared taxes could be treated as a nonequalizing grant from the center. The shared revenue received would then be deducted from the total resources available to the region in assessing the overall fiscal capacity and the need for equalizing grants.

Within this framework, it would still be possible to make adjustments to permit local governments to retain all or a portion of the relative advantage they obtain from some central grants or tax shares. For example, it might not be appropriate to equalize all sources of own-revenues, especially where these are related say to environmental costs of mining. Thus, the method allows regions keep such revenues from an environmental transfer, charge, or royalty flowing from certain natural resource projects within a specific region. However, the framework would seek to make such advantages explicit and quantifiable.

\section{Special-purpose grants}

Special-purpose grants that fall in the areas of competence of the subnational governments, hence helping the latter to meet part of their expenditure needs, might best be taken into account in the general grants scheme as a source of revenue. However, there is much less reason to take into account the spending by the center to meet its objectives in areas that do not overlap with those assigned to subnational governments - such as on defense, for example.

\section{Other revenues}

In developing countries, it may be necessary to consider donor inputs, and even activities of nongovernmental organizations (NGOs), in exactly the same way as we have treated special-purpose grants. Any funds that flow to a recipient government and can be used to satisfy some of the assessed expenditure needs can upset the equalization-based distribution and thus needs to be considered in the formulation of that distribution. It is often found that 
donor and NGO activities concentrate on the poorest of the poor regions in a nation and that the areas so selected can be "double funded" if the activities of these agencies are not considered.

\section{Including a fiscal effort adjustment}

Although the fiscal capacity models set out above do not impose performance conditions on recipients, it is possible to insert an adjustment factor for fiscal effort to the grant entitlement calculation if that is judged to be appropriate. Such a fiscal effort adjustment factor will ensure that the grant entitlement for a recipient government will be reduced if the revenue actually collected by the recipient government from its own sources falls short of its capacity to raise revenue at standard rates, and commensurately increased if collections exceed the standard. These are legitimate objectives and actions of a grant-giving government but decisions to introduce them must be made in the full knowledge that they are in conflict with any equalization objective. Similarly, recipient governments must be able to see both objectives of the granting government and be able to identify the financial impact of each objective separately. If a recipient government's grant is increased, for example, it must be able to see how much of that increase was due to each policy.

A variant of this model, which would have the objective of imposing a penalty for below-standard revenue raising effort, but not of rewarding above-standard effort, would restrict the fiscal effort adjustment to negative amounts.

\section{Phasing in equalization arrangements}

A full equalization of regional fiscal capacities, given the apparently large regional fiscal capacity differences that exist in most developing countries, may be difficult to achieve in the short term. Moreover, it may be inappropriate to seek to move rapidly in the direction of a historically determined standard, given possibly the large shifts occurring in the structure of the economy. Thus, an agreed "indicative" standard, rather than a historically based standard, may need to be used during the period of rapid structural change. Where some localities are already above these indicative standards, they can be left at their actual standard rather than have funds taken from them, and the equalization arrangements phased in to reflect both how standards are increased and how "well-off” localities are handled within the system.

\section{Which government should pay the grant?}

Although the discussion thus far has assumed the central government has a favorable fiscal imbalance, there is a question as to who should pay the equalization grant. In Canada the "equalizing grant” was paid by the central government, made possible by a vertical balance favoring the central government. ${ }^{16}$ However, in Germany, where the vertical imbalances are

\footnotetext{
${ }^{16}$ The recent changes in assignments in Canada, where provinces have been given unrestricted access to all major revenue bases (see Aubut and Sample, forthcoming), make it difficult to establish the "vertical imbalance."
} 
smaller, Länder with above-average revenue capacity make equalization transfers directly to those with below-average revenue capacity. Such cooperative arrangements are difficult to achieve in developing countries, where the struggle over scarce resources is more intense, and divisions and schisms more clearly defined. The closing of horizontal gaps in most developing countries would require a vertical imbalance in favor of a central government, together with transparent and sustainable instruments and mechanisms for redistribution. These are examined next.

\section{InSTITUTIONAL CONSIDERATIONS}

\section{Institutional arrangements, organization, and procedures}

There are a variety of practical institutional arrangements that might be engaged to facilitate the implementation of a grants system. Any institutional system for the determination of grants to local government can work well, as long as it is accepted by the center as well as the subnational governments involved. In this regard, it is highly advisable that the process is transparent and that subnational governments are involved in it.

As indicated above, countries with a British tradition have tended to adopt independent and arm's length commissions to deal with the distribution of resources across levels of government-the CGC in Australia, and the Finance Commissions in India and Pakistan. However, a continental approach has been to rely on Ministries of Interior for the administrative aspects of what initially was a deconcentration of responsibilities (e.g., in Continental European, several Latin American countries, and Indonesia). In such countries, the role of the Ministry of Finance has become increasingly important in determining the basis and estimation of grants systems, and in ensuring that the financing is made available on a timely basis.

Going forward, the options essentially relate to whether an independent commission or the Ministry of Finance should be charged with the establishment of formulae and decisions on the amounts of funds to be allocated. Often there is a shared responsibility, and the pros and cons are examined below.

A separate independent agency works best if it is given wider powers within intergovernmental financial relations but few if any functions outside that field. Critical issues in making a separate agency work well include (1) finding the right people to do the job-members should be beyond reproach and should not represent specific grant recipients or other interest groups; and (2) that politicians should set the rules and principles by which the agency operates, but should have no power to change the recommended distribution simply to meet the expectations of specific interest groups. The main advantage of such an arrangement is that it could be seen as "independent" and thus free of diktat by the center.

Some advantages of having the Ministry of Finance rather than an independent agency decide the relative needs for funding are the greater power of the ministry in getting cooperation and data, both from the local government and from central government line ministries; and in taking and implementing decisions. Its control over the macroeconomic 
parameters also predispose it to be in a better position to come to a judgment on the extent to which decisions on transfers affect overall macroeconomic stability-though this advice could also be made known to an independent commission.

The main disadvantage of the Ministry of Finance being the arbiter of the grants system is that this may be seen as the central government taking decisions on behalf of the lower levels of government and in deciding on gainers and losers. This may accentuate political fissures and difficulties and make it harder to explain unpalatable decisions to the lower levels of government.

Intermediate options are also possible-with the Ministry of Finance deciding on the overall envelope for the amounts available for transfers, and an independent agency with representation from the lower levels of government deciding on the relative distribution of the resource. It would be hard to overstate the need to give recipient governments full opportunity to make their problems and views known or for transparency in both operations and outputs.

The experience of Australia's Grants Commission is worth noting. In its full-scale reviews (reports on which are made each five years or so), the Commission:

- $\quad$ provides discussion papers simultaneously to all state governments and the national treasury, and ensures that all responses and other submissions are distributed to all parties;

- $\quad$ provides for successive rounds of submissions from the states and the national treasury so that each has full opportunity to comment on the arguments of others;

- $\quad$ holds conferences on functional or more general issues, which allow state and national government experts in such areas as education and health to exchange views with each other and the Commission;

- $\quad$ visits each state in turn to conduct discussions with officials in their capital cities and in city and country areas (including, often, very remote areas) to talk with service providers at schools, hospitals, police stations, and so on to get their "on the ground" views on service provision and cost issues;

- $\quad$ makes shorter follow-up visits to state capitals later in the review cycle to allow states to provide supplementary views;

- $\quad$ sends out its reports simultaneously to all governments;

- $\quad$ supplements its reports, as soon as possible after their release, with extensive working papers providing full details of its decisions and the reasons for them, and software that enables those that are interested to make alternative calculations; and 
- $\quad$ opens conferences to the public and provides reports and extracts of working papers free of charge to researchers.

Even in the preparation of its more routine annual update reports, the Commission provides an opportunity for the parties to comment on how it proposes to treat changes in state administrative structures and financial relations between the national government and the states (e.g., the transfer of functions from one level to another).

A grants system will have little chance of acceptance if there is a belief that it has simply been imposed from the top. Clearly, it will take much time and much patient consultation to build up confidence in the system.

\section{Information and data requirements}

The assessments on which a grants commission might recommend a distribution can be as narrow or as extensive as the available data permit. In Australia, the assessments currently cover all recurrent expenditures and revenue sources of the states, but such a wide scope is not essential and is under review. In China, where the system is still being developed, the range of assessments is being expanded and is yet far from complete in its coverage. As long as the intention to expand is indicated and the assessments that are done are not thought to take the distribution away from what might be the end result, taking short cuts is an acceptable, and often necessary, procedure.

The data required of a grant distribution system are of two types - those relating to the accounts of the recipient units of government, and those relating to the assessments of expenditure needs and revenue capacities. Unless absolutely necessary, it is better if the accounting data of the recipient governments do not influence the assessments, except to the extent that they are inputs into decisions about current average levels of service or revenue raising. As noted earlier, it is important to avoid "grant design inefficiencies" under which recipient governments can influence the size of their grant funding by changing their policies. The base data should be based on audited "past period" data if possible, as this removes the natural tendencies to underestimate revenue collections and overestimate expenses when budgeting. The use of actual data avoids these biases within the standards against which assessments might be made.

Data used in assessments can be from any source as long as they can be used to measure either differences in revenue bases, differences in the possible demand for services or differences in the unit costs of providing services, or are acceptable proxies for those variables. However, there are several attributes apart from their relevance to the assessments that make some data more appropriate than others do for the task. These are that:

- $\quad$ The data should be available for each unit of government. If not, it must be possible to use the data for one region as also being an appropriate indicator of need in others. This is sometimes possible when measuring differences in unit cost, but rarely otherwise. 
- The data should be comparable across units of government. This is important to the end result and is usually a very time-consuming task. Lack of comparability and inaccuracies in the data can have major distributional consequences.

- $\quad$ The data should preferably be sourced to an independent authority. This is important to minimize "grant design inefficiencies" and most countries use their central statistical agencies extensively as a source of these data.

- $\quad$ The data should be known to be updated annually or on some other known frequency such as at the time of a national population census, data from which will usually be a major source of information. It is important that the system not be subject to either constant changes as data become unavailable, or to rapid changes in distribution of funding because of changes in assessment methods. Stability of data sources usually gives greater stability of results.

The data used for revenue assessments will often need to be tailored to the legislative base of the revenue source being assessed. While GDP per capita, for example, might be thought to be an adequate measure of differences in the value of land being used for productive purposes, it is obviously better if the actual value of that land, based on a standard approach to valuing, can be collected. It might be acceptable in such cases to derive the data from the recipient governments if it is known to be sufficiently comparable and free of manipulation.

Such direct measures of a revenue base are not always available and general measures of economic activity, such as GDP per capita, household income, or value added by an industry sometimes need to be used. Such data are often unreliable at anything less than "whole-of-nation" level and should be looked at closely for comparability before being used.

When looking at data on which to base expenditure needs assessments, those relating to differences in demand are much more likely to be available than those relating to unit cost differences. Data on where demand for services is emanating from is often used as a management tool, and similarities between regions in their management task will often create similarities in the data they collect.

Influences on regions' unit costs differ widely and are much more difficult to measure. Even on the demand side, however, it will be easier to get data on raw measures of demand such as the number of school age children than it will be to get information on the extent to which different types of students in the appropriate age group might have different demand patterns. It is easy enough to show that old people use more hospital services per capita than the average, and to count the relative number of old people in each region's population, but much harder to decide what weighting to use when calculating their relative impact on demand for services.

Matching the use of actual financial standards, past period nonfinancial data in the expenditure and revenue assessments are generally used. This is a natural consequence of there rarely being forecasts of the range of data needed to make assessments based on the year for which the grants are being determined. 
Before the assessments are finalized, it is beneficial to give them a "reality" check to make sure they are sufficiently robust to be accepted in the regions. It is particularly important here to see that the assessments of those regions that are to be detrimentally affected can be justified. The best way to do this reality check is to have gathered policy information on at least the big issues in each function and know why a region's per capita expenditure or revenue might be expected to be greater or less than that in other regions. It is particularly important, where relevant, to be able to show that a region has a particularly low or high figure because of a different policy approach. Making such information available is part of the transparency of the system that we believe to be vital to its acceptance.

In Australia, the information on policy differences was originally collected by the Commission because no other government agency saw a need for it. However, it is now seen as critical to improving national public sector efficiency and is collected by the Productivity Commission, a central government authority charged with responsibility for recommending how this can be achieved. The states in Australia now habitually look at the comparable financial and nonfinancial data when setting their budgets and the central government agencies responsible for distributing special-purpose funds among the states also use it.

\section{CONCLUSIONS}

The design of grant systems and the mix of instruments used reflect the constitutional framework, institutional and political constraints, and forces underlying the division of responsibilities and resources in a country. The magnitude of the grants should be determined by overall fiscal sustainability exercises for "general government," but the distribution of resources across regions often reflects political economy considerations.

While special-purpose grants continue to be important in preserving the interests of the central government, there is a possibility of "game playing” by subnational governments, possible limitations on monitoring use of such grants (especially in developing countries), and likely adverse effects on horizontal disparities if matching conditions are used. Under these conditions, there is greater reliance on "looser" block grants, coupled with monitorable contracts.

Given the extent of vertical imbalances, a central government is likely to have a role to play in horizontal equalization. Decisions are also needed as to whether the special-purpose grants might be taken into account in this assessment of equalization transfers. In order to enhance "fairness" and incentives for more effective resource use, a combination of revenue capacities and expenditure needs might be used as the basis for the design of an equalization grants system. Thus, the first question faced by many designers of assessment-based grants distribution systems is whether the assessments are to cover both revenue capacities and expenditure needs. The question of the standard to which the regions are to be equalized is also very important.

There are several approaches that can be taken to measuring the differences between regions in revenue capacity and expenditure needs. The appropriateness of using these approaches changes as a grants system evolves and the data and other information systems improve. It is 
important to keep some flexibility in the design of the grants system, as fiscal policy evolves in response to changing circumstances in all cases.

In order to minimize arbitrariness, it is useful to place the administration of the grants system in as much of a cooperative arrangement as possible, involving explicit involvement of subnational interests. Whether this is arranged under the aegis of a ministry of finance or an independent commission will depend on the circumstances of a particular country. 


\section{References}

Ahmad, Ehtisham, 1993, "Poverty, Demographic Structure and Social Protection Policy," in On the Role of Budgetary Policy during Demographic Changes, ed. by B. Wolfe, Public Finance, Vol. 48.

— - ed., 1997, Financing Decentralized Expenditures, an International Comparison of Grants (Cheltenham, United Kingdom; Brookfield, Vermont: Edward Elgar).

— Gao Qiang, and Vito Tanzi, eds., 1995, Reforming China’s Public Finances (Washington: International Monetary Fund).

— , and Eric Mottu, 2003, "Oil Revenue in Federal Systems: Issues and Country Experience,” in Fiscal Policy Formulation and Implementation in Oil Producing Countries, ed. by J. Davis, R. Ossowski, and A. Fedelino (Washington: International Monetary Fund).

, Mario Fortuna, and Raju Singh, 2004, “Towards More Effective Redistribution: Reform Options for Intergovernmental Fiscal Relations in China,” IMF Working Paper 04/98 (Washington: International Monetary Fund).

— , and Giorgio Brosio, Handbook of Fiscal Federalism (Cheltenham, United Kingdom; Brookfield, Vermont: Edward Elgar) (forthcoming).

Aubut, Julie, and Robert Sample, “Decentralization: the Canadian Experience,” in Managing Subnational Fiscal Operations, ed. by Ehtisham Ahmad and others (Washington: International Monetary Fund) (forthcoming).

Boadway, R, “Intergovernmental Transfers and Equity,” in Handbook of Fiscal Federalism, ed. by Ehtisham Ahmad and Giorgio Brosio (Cheltenham, United Kingdom; Brookfield, Vermont: Edward Elgar) (forthcoming).

— Canadian Tax Foundation).

Brosio, G., 1995, “Local Taxation in an International Context,” in Reforming China's Public Finances, ed. by Ehtisham Ahmad, Gao Qiang, and Vito Tanzi (Washington: International Monetary Fund).

Clark, Douglas H., 1997, “The Fiscal Transfer System in Canada,” in Financing Decentralized Expenditures, an International Comparison of Grants, ed. by Ehtisham Ahmad (Cheltenham, United Kingdom; Brookfield, Vermont: Edward Elgar). 
Commonwealth Grants Commission, 2004, Report on State Revenue Sharing Relativities, 2004 Review (Commonwealth of Australia).

Commonwealth Grants Commission, Report on State Revenue Sharing Relativities, 2004 Review, Supporting Information (Commonwealth of Australia).

Govinda, Rao, 2002, “Fiscal Decentralization in Indian Federalism,” in Ahmad and Tanzi (2002).

Levtchenkova, S., and J. Petchey, “A Model for Public Infrastructure Equalization,” in Challenges in the Design of Fiscal Equalization and Intergovernmental Transfers, ed. by J. Martinez-Vazquez, R. Bahl, and R. Searle, forthcoming.

Lotz, J., 1997, “Denmark and Other Scandinavian Countries: Equalization and Grants,” in E. Ahmad (ed.), 1997.

— 2005, Danish Grant Policy: How Best to Influence Local Authority Behavior, (Copenhagen: Ministry of Finance).

Searle, R., Federal Fiscal Relations in Australia-2001, 2002, ICER Working Paper No. 01/2002 (Torino, Italy: International Centre for Economic Research).

- The Australian Fiscal Equalisation System and Capital Transactions, the Final Step, 2002, ICER Working Paper No. 02/2002 (Torino, Italy: International Centre for Economic Research).

— 2004, "Revenue Sharing, Natural Resources and Fiscal Equalization,” in Challenges in the Design of Fiscal Equalization and Intergovernmental Transfers, ed. by J. Martinez-Vazquez, R. Bahl, and R. Searle.

Shah, Anwar, 1995, “Theory and Practice of International Transfers,” in Reforming China's Public Finances, ed. by Ehtisham Ahmad, Gao Qiang, and Vito Tanzi (Washington: International Monetary Fund).

Ter-Minassian, Teresa, eds.,1997, Fiscal Federalism in Theory and Practice (Washington: International Monetary Fund). 